\title{
The behaviour of $\mathbf{f} 2$ coliphage in activated sludge treatment
}

\author{
By S. A. BALLUZ, M. BUTLER AND H. H. JONES \\ University of Surrey, Guildford, Surrey
}

(Received 1 August 1977)

\begin{abstract}
SUMMARY
A model activated sludge treatment plant was used which was functionally very similar to a full-scale plant. It was inoculated with $\mathrm{f} 2$ coliphage and the titres of virus in the influent, the mixed liquor and the effluent were monitored regularly. The distribution of the virus in the solids and liquid fractions of the mixed liquor was in the ratio of $18: 82$ and $20.4 \%$ of the influent virus was recovered in the effluent. After inoculation was stopped the titre of virus in the solids fraction of the mixed liquor remained high and unaltered for up to $70 \mathrm{~h}$, whereas the value for effluent reverted to the low background titre originally present. These results are discussed in relation to those reported for poliovirus and it is concluded that f2 coliphage is not a suitable model for studies of the behaviour of human enteroviruses.
\end{abstract}

\section{INTRODUCTION}

Carstens, Coetzee, Malherbe \& Harwin (1965) suggested that bacteriophage would be a suitable model for indicating the efficiency of sewage treatment for the removal of viruses. This was quickly followed by the more specific recommendation from Buras \& Kott (1966) that the f2 coliphage, a picornavirus, might be a highly suitable indicator for the behaviour of human enteroviruses. More recently, Kott, Roze, Sperber \& Betzer (1974) reiterated this claim supported by data on the relative frequency of $f 2$ coliphage and human enteric viruses in both percolating filters and oxidation-pond effluents examined at different times of the year. Since then there have been several reports on the distribution and survival of inoculated f2 coliphage in full-scale and pilot-scale plants. For instance, Naparstek, Olivieri, Kawata \& Sherman (1976) monitored the survival of the virus in the different treatment stages of activated sludge treatment and final chlorination. As expected the highest reduction of virus $(72 \%)$ was observed after chlorination but some reduction also occurred after the preliminary comminutor treatment $(\mathbf{7 . 5 \%})$, aeration $(11.1 \%)$, sedimentation $(46.8 \%)$ and sand filtration $(22 \cdot 2 \%)$, giving a cumulative reduction of $80.5 \%$ which confirmed a rate of $80.2 \%$ reported earlier (Naparstek, 1973) for a larger treatment plant, 2.9 as opposed to 0.75 million gallons/day.

A pilot scale study has been reported by Safferman \& Morris (1976) who seeded f2 coliphage into a three-stage activated sludge plant processing 80000 gallons/day. This type of complex treatment plant, which introduces a sequence of nitrification, clarification and denitrification stages, is very efficient and there was a reduction 
of phage across the plant of about $99.97 \%$. The greatest reduction rates were observed in the denitrification and high-rate activated sludge stages, each effecting at least $95 \%$ reduction of the relevant influent virus titre.

The removal of $f 2$ coliphage by percolating filter sewage treatment plants has also been investigated. Sherman, Kawata, Olivieri \& Naparstek (1975) seeded two full-scale plants with virus and monitored it through all the treatment stages (grit chamber, comminutor, primary settling, filtration, secondary settling and chlorination) and showed a reduction across the plant of 70.0 to $80.0 \%$ including the chlorination stage. Reduction across the trickling filter alone, however, was low and ranged from $9 \cdot 0$ to $18.9 \%$.

In general, it would appear from these observations that the behaviour of $\mathrm{f} 2$ coliphage in sewage treatment was similar to that of poliovirus although Ranganathan, Malina, Sagik \& Moore (1974) produced evidence from radioactive tracer studies that $\mathbf{f} 2$ coliphage did not behave exactly like poliovirus. However, Balluz, Jones \& Butler (1977), pointed out that there are inherent difficulties in interpreting the results of such complex studies in sewage and it was thought desirable to investigate the behaviour of $\mathrm{f} 2$ coliphage under conditions similar to those they used for poliovirus, giving special attention to the association of the virus with the solids fractions of the mixed liquor.

\section{MATERIALS AND METHODS}

\section{Activated sludge treatment plant model}

The model based on that devised by Curds \& Fey (1969) and modified by Balluz, Jones \& Butler (1977) was used (Plate 1).

\section{Propagation of stock virus and bacterial host}

Eschericia coli (K12 Hfr) and the f2 coliphage were obtained from Dr J. Slade, Thames Water Authority.

The bacterial culture was grown at $37{ }^{\circ} \mathrm{C}$ in $3 \%$ tryptose soya broth and vigorously aerated until a titre of approximately $10^{8 \cdot 3}$ cells $/ \mathrm{ml}$ was reached. Sufficient $\mathrm{f} 2$ coliphage was added at this stage to achieve a multiplicity of 5 coliphage particles to each bacterium and the culture was re-aerated vigorously at $37^{\circ} \mathrm{C}$ for approximately $3 \mathrm{~h}$ by which time the bacteria were lysed and the medium had become clear.

Chloroform $(10 \%)$ was added and mixed vigorously with the culture which was then allowed to stand at room temperature for $10 \mathrm{~min}$. It was then centrifuged (5000 g, for $10 \mathrm{~min}$ at $20^{\circ} \mathrm{C}$ ) and the aqueous supernatant was removed and stored over $10 \%$ chloroform at $4{ }^{\circ} \mathrm{C}$ until required.

\section{Titration of virus}

The procedure for plaque assay was according to d'Herelle's soft agar technique as described by Adams (1959). The volume of the inoculum was $0.5 \mathrm{ml} / \mathrm{plate}$, taken from a tenfold serial dilution prepared in dilution fluid containing peptone $(0.1 \%)$, sodium chloride $(0.03 \%)$ with $\mathrm{MgSO}_{4}(0.0005 \mathrm{M})$ and tris (hydroxymethyl 
methylamine) buffer $(0 \cdot 01 \mathrm{~m}$ at $\mathrm{pH} 7 \cdot 8)$. The lawn agar was prepared by a modification of the method of Loeb \& Zinder (1961). The medium contained Bacto tryptone $(1 \%)$, yeast extract $(0.5 \%)$, sodium chloride $(0.5 \%)$ and glucose $(0.1 \%)$ and was adjusted to $\mathrm{pH} 7.0$ with $\mathrm{N}$-sodium hydroxide, after which calcium chloride and magnesium sulphate were each incorporated at a final molarity of $0 \cdot 0025$. For the soft agar technique the medium contained nutrient broth $(0.8 \%)$ and sodium chloride $(0.5 \%)$ in $0.65 \%$ agar.

The results of the titrations were expressed as plaque forming units $/ \mathrm{ml}$ (p.f.u./ml).

\section{Inoculation of the plant and sampling}

The reservoir of influent settled sewage was inoculated with sufficient virus to give an average initial titre of $10^{5 \cdot 9}$ p.f.u. $/ \mathrm{ml}$. The retention time of the plant was kept at $5.4 \mathrm{~h}$ and the temperature and suspended solids at $15{ }^{\circ} \mathrm{C}$ and 4000 parts $/ 10^{6}$ respectively.

Samples $(5 \mathrm{ml})$ of the influent, mixed liquor and effluent were taken at intervals and to each was added $0.5 \mathrm{ml}$ chloroform which was thoroughly mixed with the sample in order to destroy viable bacteria. After this treatment the samples of influent and effluent were stored at $4{ }^{\circ} \mathrm{C}$ to await later assay. The mixed liquor was fractionated by centrifugation $\left(1500 \mathrm{~g}\right.$, for $10 \mathrm{~min}$ at $\left.20^{\circ} \mathrm{C}\right)$ after the chloroform had been evaporated by bubbling nitrogen gas through it. The supernatant (liquid fraction) was decanted and stored at $4{ }^{\circ} \mathrm{C}$. The deposit (solids fraction) was resuspended to a final volume of $5 \mathrm{ml}$ in the dilution fluid containing $10 \%$ calf serum. It was then subjected to ultrasonic treatment with an MSE 150 watt $20 \mathrm{kHz}$ ultrasonic disintegrator with a logarithmic probe No. 34041 at $13 \mu \mathrm{m}$ for $1 \mathrm{~min}$ at $2{ }^{\circ} \mathrm{C}$. After treatment the sample was stored with the other samples at $4{ }^{\circ} \mathrm{C}$. All samples were assayed within $48 \mathrm{~h}$ of sampling.

\section{RESULTS}

In the period before the introduction of $\mathrm{f} 2$ coliphage some unspecified bacteriophage activity was detected in the influent, mixed liquor and effluent (Fig. 1). The greatest background titre was detected in the influent and the effluent titre was $19 \%$ of this (Table 1). In the mixed liquor the solids fraction carried the greater proportion of the detectable phage with the ratio between solids and liquid fraction being $68 \cdot 6: 31 \cdot 4$. No attempt was made to characterize the phage beyond the observation that it produced plaques in the bacterial host which were more or less similar to those produced by $\mathrm{f} 2$ coliphage.

After inoculation of the influent reservoir with $\mathrm{f} 2$ coliphage the titres of virus rapidly increased in both the mixed liquor and effluent and reached a plateau by about $20 \mathrm{~h}$ later (Fig. 1). Thereafter the phage titres remained constant and in the mixed liquor the phage was distributed between the liquid and solids fractions in the ratio 84:16 respectively (Table 1). The titre of phage in the effluent was about $20.4 \%$ of that in the influent which indicated that the total reduction across the plant was $79 \cdot 6 \%$. 


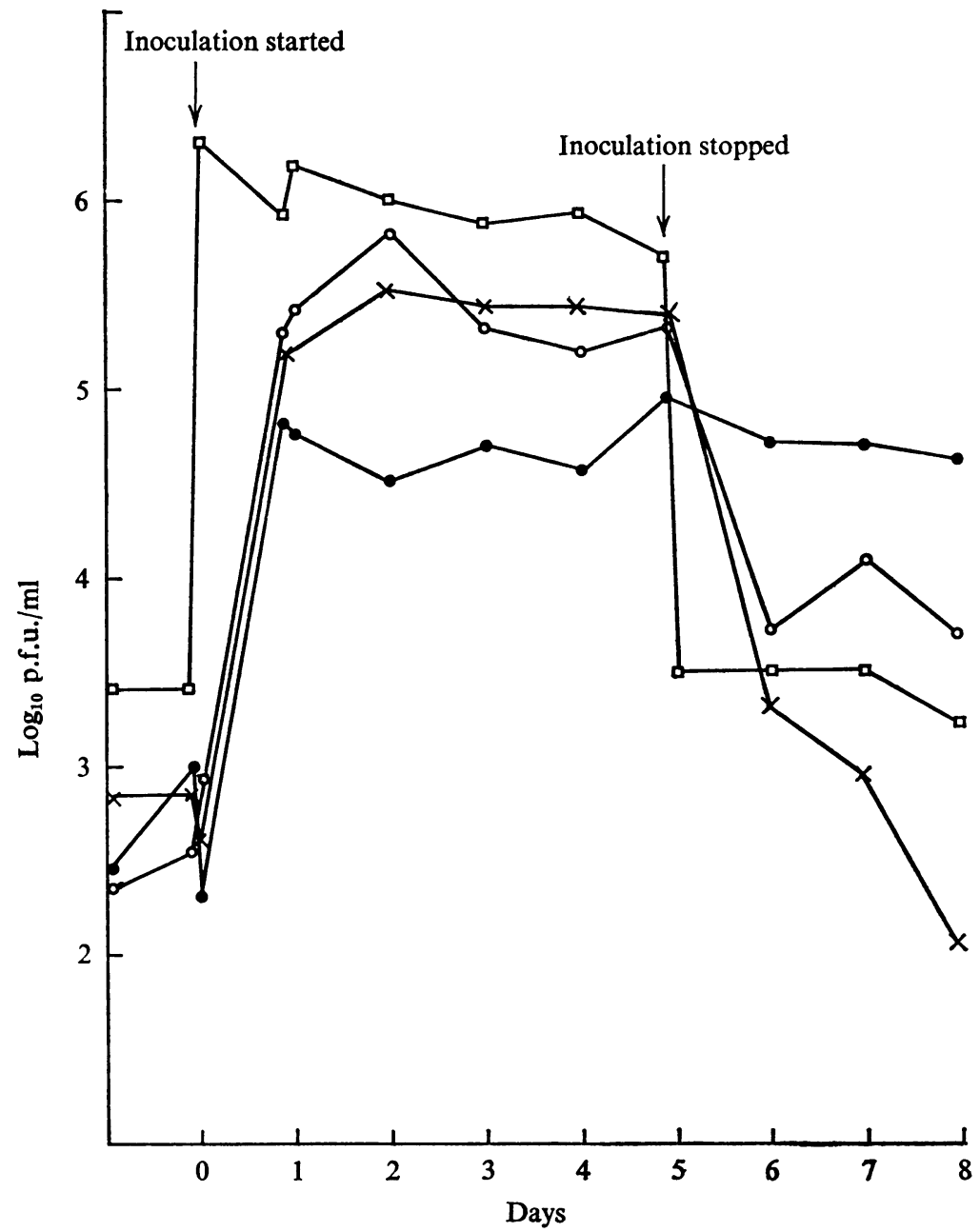

Fig. 1. Distribution of virus in the model plant before, during and after cessation of inoculation with virus. Virus in raw settled sewage $(\square-\square)$, effluent $(x-x)$, mixed liquor liquid fraction $(\mathrm{O}-\mathrm{O})$ and mixed liquor solids fraction (O-O).

When the influent reservoir was replaced with normal influent sewage, the titres of $\mathrm{f} 2$ coliphage in the effluent dropped quite sharply to a value about the same as that recorded before inoculation (Table 1). However, in the mixed liquor, even $70 \mathrm{~h}$ after inoculation had ceased the phage titre in the solids fraction remained almost as high as during inoculation, while that in the liquid fraction, although also declining quickly, maintained a value which was greater than that recorded before inoculation. The reduction across the plant at this time appeared less efficient $(26 \cdot 3 \%)$ than during the period of inoculation (Table 1 ) but the titre of phage in the effluent was obviously influenced, in particular, by residual virus associated with the mixed liquor solids. 
Table 1. Distribution of $f 2$ coliphage on different parts of the model activated sludge plant before, during and after inoculation

$\begin{array}{lclc} & \text { Preinoculation* } & \text { Inoculation } & \text { Post inoculation } \\ \text { Influent } & 3.24 & 6 \cdot 01 & 3 \cdot 44 \\ \text { Mixed liquor } & & & \\ \quad(a) \text { Liquid fraction } & 2 \cdot 54(31 \cdot 4) \dagger & 5 \cdot 38(84) \dagger & 3 \cdot 93(36) \dagger \\ \text { (b) Solids fraction } & 2 \cdot 88(68 \cdot 6) \dagger & 4 \cdot 66(16) \dagger & 4 \cdot 17(64) \dagger \\ \quad(c) \text { Total } & 3 \cdot 04 & 5 \cdot 45 & 4 \cdot 37 \\ \text { Effluent } & 2 \cdot 52(19) \ddagger & 5 \cdot 32(20 \cdot 4) \ddagger & 2 \cdot 86(26 \cdot 3) \ddagger\end{array}$

* Preinoculation figures: the mean of 25 samples collected from time to time; inoculation figures: the mean of samples collected between days 1 and 5; post inoculation figures: the mean of samples collected between days 6 and $8\left(\log _{10}\right.$ p.f.u. $\left./ \mathrm{ml}\right)$.

$\dagger \%$ of the total titre of mixed liquor.

$\ddagger \%$ of appropriate influent titre.

\section{DJSCUSSION}

Bacteriophages are invariably present in raw settled sewage of domestic origin but it was thought unlikely that the background titres which were detected would affect the interpretation of the subsequent experimental values since they represented only $0.3 \%$ of the titre achieved after the addition of f2 coliphage. Furthermore, it was assumed that neither the background nor added bacteriophage replicated in host cells at $15^{\circ} \mathrm{C}$ which was the temperature of the plant.

After the addition of $\mathrm{f} 2$ coliphage it was not surprising that the titre in the mixed liquor and effluent soon rose to plateaux and continued at those levels, with minor variations until inoculation was discontinued. It was noted that the ratio of virus in the liquid and solids fractions before and during inoculation differed (31:68 and $84: 16)$ possibly indicating that the solids had become saturated with adsorbed virus at the higher dose rate although this did not appear to affect the general efficiency of the plant. However, what was of particular interest was that the behaviour of the phage was different from that previously reported for poliovirus in the same model activated sludge plant (Balluz, Jones \& Butler, 1977). The most striking contrast was in the distribution of the two viruses between the liquid and solids fractions of the mixed liquor. Thus, the values for $\mathrm{f} 2$ coliphage were $84: 16$ and for poliovirus were virtually the opposite at 15:85. Another dissimilarity was the percentage removal of virus across the plant, which for the phage was $79.6 \%$ and for poliovirus $99.96 \%$, which implied that the efficiency of the plant for the removal of poliovirus was very much greater than for $\mathrm{f} 2$ coliphage. The fact that the value for the reduction of phage was somewhat greater than that reported by Naparstek et al. (1976) which was $66 \%$ (calculated from their figures excluding the final chlorination stage) presumably reflects the differences in the function of the two plants, model and full-scale.

Another feature of great interest was that, in complete contrast to poliovirus, the titre of $\mathrm{f} 2$ coliphage in the solids fraction of the mixed liquor was relatively low yet remained stable after the inoculation stopped which implied that the phage was 
more strongly bound to the solids than poliovirus; this may not be surprising if the phage had an affinity for the bacteria present in the sludge.

The main implications of these dissimilarities between the behaviour of $\mathrm{f2}$ coliphage and poliovirus are that the phage is an unsuitable indicator for the behaviour of human picornaviruses and that in studies of viruses in sewage it may well be necessary to examine the behaviour of each virus individually.

The work was supported by the Thames Conservancy division of the Thames Water Authority and one of us (S.A.B.) is indebted to the Lebanese National Council for Scientific Research for a studentship.

\section{REFERENCES}

Adams, M. H. (1959). Bacteriophages. New York: Interscience Publishers.

Balluz, S. A., Jones, H. H. \& BUTler, M. (1977). The persistence of poliovirus in activated sludge treatment. Journal of Hygiene 78, 165-73.

BURAS, N. \& KOTT, Y. (1966). Bacteriophage as an indicator for the estimation of water pollution. Israel Journal of Medicine 2, 660-61.

Carstens, E. M. J., Coetzee, O. J., MalHerbe, H. H. \& Harwin, R. H. (1965). Bacteriophage of Serratia marcescens as an index of human virus survival during sewage purification. CSIR (South African Council for Scientific and Industrial Research) Report. Research 241, 1-17.

CuRds, C. R. \& Fey, G. J. (1969). The effect of ciliated protozoa on the fate of E. coli in the activated sludge process. Water Research 3, 853-67.

Kott, Y., Roze, N., Sperber, S. \& Betzer, N. (1974). Bacteriophages as viral pollution indicators. Water Research 8, 165-71.

LoEB, T. \& ZINDER, N. D. (1961). A bacteriophage containing RNA. Proceedings of the National Academy of Sciences of the U.S.A. 47, 282-9.

NAPARSTEK, J.D. (1973). Virus removal by activated sludge using an f2 coliphage model. Sc.M. thesis, The Johns Hopkins University, Baltimore.

Naparstek, J. D., Olivieri, V. P., Kawata, K. \& Sherman, V. R. (1976). Virus removal in an activated sludge plant. Water and Sewage Works, Reference Number R16-20.

Ranganatham, K. R., Manina, J. F., Jr., SAgIK, B. P. \& Moore, B. D. (1974). The inactivation of poliovirus, bacteriophage of $E$. coli $\mathrm{B}$ and enteric bacteria in biological waste treatment systems. Technical Report to National Science Foundation, Research Applied to National Needs. University of Texas, Center for Research in Water Resources, CRWR 111, EHE - 74-03, 100 pp.

Safferman, R. S. \& Morris, M. E. (1976). Assessment of virus removal by a multi-stage activated-sludge process. Water Research 10, 413-20.

Sherman, V. R., Kawata, K., Otivieri, V. P. \& Naparstek, J. D. (1975). Virus removals in trickling filter plants. Water and Sewage Works. Reference number R36-R44.

\section{EXPLANATION OF PLATE}

\section{Prate 1}

Laboratory model activated sludge plant. 
Journal of Hygiene, Vol. 80, No. 2

Plate 1

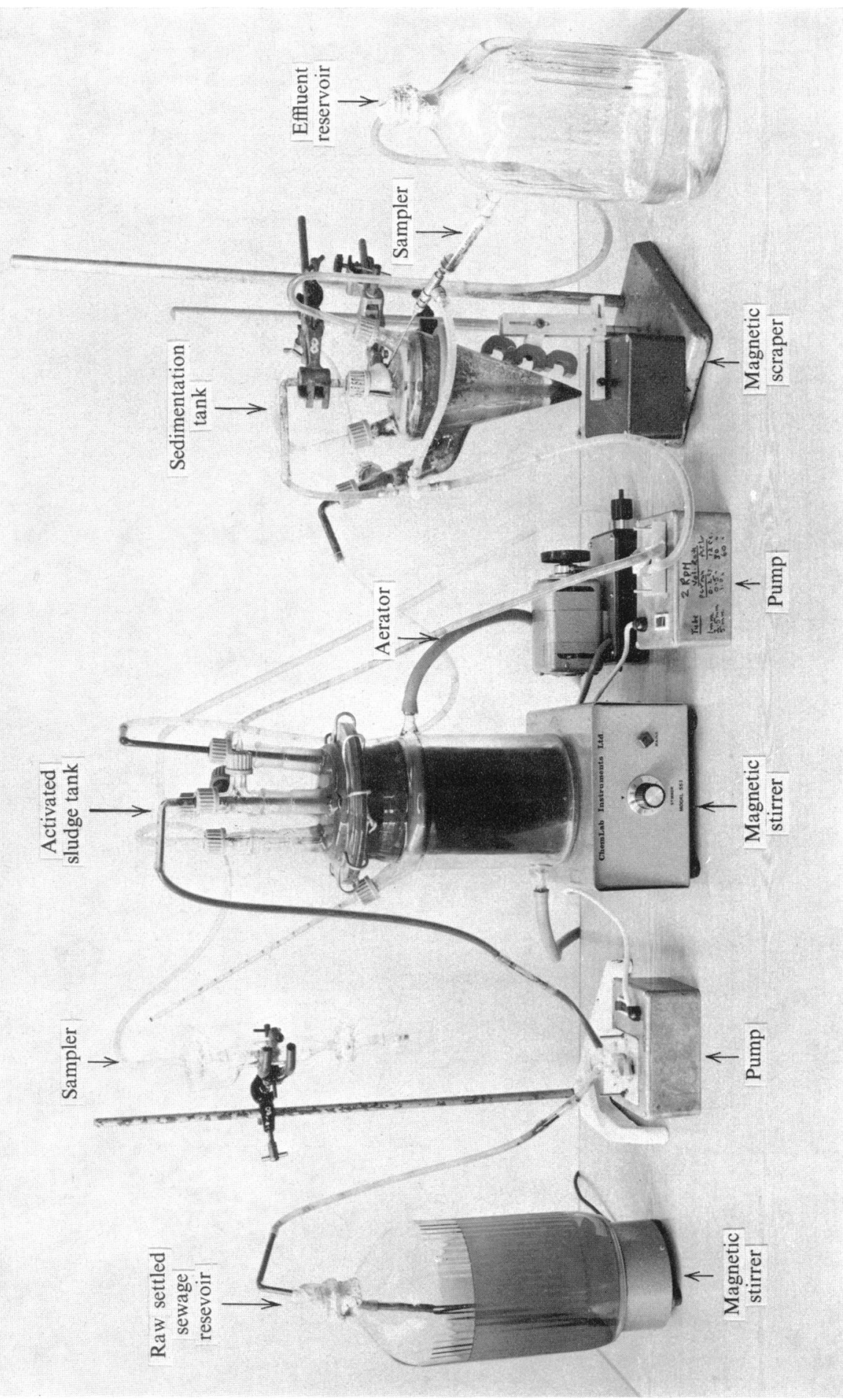

S. A. BALLUZ, M. BUTLER AND H. H. JONES

(Facing p. 242) 